\title{
Penicillin-binding Proteins of the Stalk of Caulobacter crescentus
}

\author{
By SHIGEO KOYASU, ${ }^{1}{ }^{*} \dagger$ AKIO FUKUDA, ${ }^{1} \ddagger$ YOSHIMI OKADA ${ }^{1}$ AND \\ JEANNE S. POINDEXTER ${ }^{2}$ \\ ${ }^{1}$ Department of Biophysics and Biochemistry, Faculty of Science, University of Tokyo, Hongo, \\ Tokyo 113, Japan \\ ${ }^{2}$ Department of Microbiology, The Public Health Research Institute of the City of New York, \\ New York, NY 10016, U.S.A.
}

(Received 25 January 1983; revised 27 April 1983)

Properties of stalks isolated from Caulobacter crescentus were studied. Isolated stalks possessed a
density close to that of the cellular outer membrane, and contained a very low activity of
succinate dehydrogenase. The protein patterns were similar to those of the outer membrane.
These results suggest that the membrane component of the $C$. crescentus stalk comprises mainly
outer membrane. The patterns of penicillin-binding proteins (PBPs) in isolated stalks were
different from those of total cell envelopes. The stalks possessed neither PBP 1A nor PBP 3
which is localized in the inner membrane of growing cells. PBP X (mol. wt 93000) and PBP Y
(mol. wt 85000 ), which are minor PBPs in the total cell envelope fraction were greatly enriched
in the isolated stalks. A mecillinam-resistant, stalk-defective mutant, C. crescentus CB15 mcr-
816 , lacked both PBP X and PBP Y. It is concluded that PBP X and PBP Y are localized mainly
in the stalk. Whether they are involved in the stalk development remains to be investigated.

\section{INTRODUCTION}

Caulobacter, a genus of Gram-negative stalked bacteria, is distinguished by a unique, asymmetric type of cell division in which a motile swarmer cell and a nonmotile stalked cell are produced by fission. Morphogenesis of polar surface structures follows an apparently invariable sequence in each cell cycle (Poindexter, 1964, 1981; Shapiro, 1976). The stalk is the characteristic polar structure. Other polar structures include a flagellum, pili and DNA phage receptor sites that are formed at the older pole of the swarmer cell. Upon transition of the swarmer cell into a stalked cell, the stalk arises at the same site that previously bore the other polar surface structures. The stalk elongates at the juncture with the cell during the subsequent cell division cycle (Schmidt \& Stanier, 1966). The stalk contains a peptidoglycan layer that extends continuously from the lateral cell wall, and crossbands that traverse or encircle the stalk core and are sensitive to lysozyme (Poindexter \& Cohen-Bazire, 1964; Schmidt \& Stanier, 1966; Jones \& Schmidt, 1973; Schmidt, 1973; Poindexter \& Hagenzieker, 1982).

Penicillin-binding proteins (PBPs) are known that are peptidoglycan synthetic enzymes and are involved in cell wall biosynthesis, cell division and cell morphogenesis (Spratt, 1975, 1977a, b; Spratt \& Pardee, 1975; Tamaki et al., 1977; Suzuki et al., 1978; Nakagawa et al., 1979; Ishino et al., 1980; Suzuki et al., 1980; Tamura et al., 1980; Ishino \& Matsuhashi, 1981 ; Nakagawa \& Matsuhashi, 1982). In order to study such problems as functional localization of PBPs and the involvement of PBPs in the maintenance and/or formation of bacterial cell shape, Caulobacter

† Present address: The Tokyo Metropolitan Institute of Medical Science, 3-18-22 Honkomagome, Bunkyo-ku, Tokyo 113, Japan.

‡ Present address: Hoechst Research and Development Laboratories, 1-3-2 Minami-dai, Kawagoe-shi, Saitama 350, Japan.

Abbreviation: PYE, polypeptone-yeast extract. 
crescentus can serve as an especially useful organism because of its unique morphology and morphogenesis. It is especially of interest to study how PBPs may be involved in the stalk development, since differences in composition between cellular peptidoglycan and stalk peptidoglycan have been observed (Poindexter \& Hagenzieker, 1982).

Previous studies (Koyasu et al., 1980, 1981, 1982) revealed that $C$. crescentus CB15 possesses at least five major PBPs [namely, PBP 1A (mol. wt 132000), PBP 1Bs (mol. wt 98000), PBP 2 (mol. wt 77000), PBP 3 (mol. wt 64000) and PBP 4 (mol. wt 50000)] in the cell envelope, and three PBPs [PBP S1 (mol. wt 60000), PBP S3 (mol. wt 45000) and PBP S4 (mol. wt 40000)] in the cellular soluble fraction. Caulobacter crescentus $\mathrm{CB} 13$, an independent isolate, possesses at least four PBPs (PBP 1A, PBP 1Bs, PBP 2 and PBP 3) in the cell envelope, and four PBPs [PBP S1, PBP S2 (mol. wt 55000), PBP S3 and PBP S4] in the soluble fraction. Some of the $C$. crescentus PBPs are very different in their properties from those of other Gram-negative bacteria. PBP 4 of C. crescentus CB15 is localized in outer membranes, whereas PBPs of other bacteria are detected mostly in inner membranes. PBP S1 and PBP S2 that show penicillinase-like activity are observed in the cellular soluble fraction, whereas similar low molecular weight PBPs of other bacteria that also show penicillinase-like activity are detected in the cell envelope fraction. Caulobacter crescentus PBP 3 is suggested to be involved in the process of cell division (Koyasu et al., 1981).

Stalk-abscission mutants of $C$. crescentus release stalks into the culture medium (Poindexter, 1978). The shed stalk possesses a swelling at the end that corresponds to the juncture with the cell, where stalk materials are synthesized (Schmidt \& Stanier, 1966; Poindexter, 1978; Poindexter \& Hagenzieker, 1982). These mutants make it possible to study the properties of stalks and stalk PBPs, and to approach the question of whether there are any PBPs related to the stalk or stalk development that are different from those PBPs that are involved in lateral wall synthesis and cell division.

\section{METHODS}

Bacterial strains and growth conditions. Caulobacter crescentus CB15 wild-type, $C$. crescentus CB15 str-802, a streptomycin-resistant mutant (Fukuda et al., 1981) and C. crescentus CB15 NY106, an abscission mutant that releases its stalk (Poindexter, 1978) were used. Bacteria were grown at $30^{\circ} \mathrm{C}$ in polypeptone-yeast extract (PYE) broth (Poindexter, 1964) supplemented with $0.45 \mathrm{mM}-\mathrm{CaCl}_{2}$ or in minimal $0.6 \%(\mathrm{v} / \mathrm{v}) \mathrm{HiGg}$ medium that contained $0.3 \%(\mathrm{w} / \mathrm{v})$ glucose, $0.3 \%(\mathrm{w} / \mathrm{v})$ monosodium glutamate, $0.1 \mathrm{mM}-\mathrm{Na}_{2} \mathrm{HPO}_{4}$, and $0.1 \mathrm{mM}-\mathrm{K}_{2} \mathrm{HPO}_{4}$, pH 7.0 (Poindexter, 1978; Poindexter \& Hagenzieker, 1982). Stalks are longer in $0.6 \% \mathrm{HiGg}$ medium than in PYE broth.

Preparation of cell envelopes and stalks. Cell envelopes were prepared as described previously (Koyasu et al., 1980, 1981). Briefly, harvested cells were sonicated in a Branson Sonifier, and after removal of cell debris by lowspeed centrifugation, envelopes were sedimented by ultracentrifugation. Shed stalks of $C$. crescentus CB15 NY106 were prepared as described (Poindexter \& Hagenzieker, 1982). Bacteria were grown in $0.6 \% \mathrm{HiGg}$ to stationary phase, at which point stalks are released into the culture medium. Shed stalks were collected by repeated differential centrifugation and suspended in $10 \mathrm{~mm}$-sodium phosphate buffer, $\mathrm{pH} 7 \cdot 0$.

Stalks of $C$. crescentus CB15 wild-type were prepared as follows. Cells were grown in $0.6 \% \mathrm{HiGg}$ to stationary

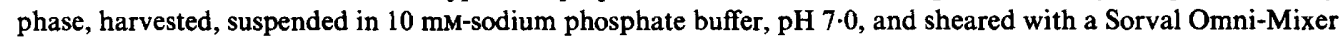
at setting 7 for $4 \mathrm{~min}$. Sheared stalks were also collected by repeated differential centrifugation and finally suspended in $10 \mathrm{mM}$-sodium phosphate buffer, $\mathrm{pH} 7 \cdot 0$. This preparation was contaminated with some broken cells and membranes. For further purification, ultracentrifugation in an isopycnic sucrose density gradient was carried out.

Isopycnic sucrose gradient centrifugation. Gradient centrifugation was carried out as described by Koyasu et al. (1980). Samples were suspended in $1.5 \mathrm{ml} 25 \%$ (w/v) sucrose, $5 \mathrm{mm-EDTA}$, pH 7.5. In some experiments, stalk samples were sonicated at setting 3 for $5 \mathrm{~min}$ beforehand, in an attempt to dissociate inner and outer membranes.

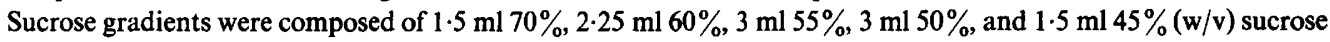
solutions, each containing $5 \mathrm{mm-EDTA}$, pH 7.5. The stalk suspensions were centrifuged to equilibrium at 38000 r.p.m. for $22 \mathrm{~h}$ at $6{ }^{\circ} \mathrm{C}$ in a Hitachi RPS40T rotor. After collection, stalk fractions were diluted with three volumes of $10 \mathrm{~mm}$-sodium phosphate buffer, $\mathrm{pH} 7 \cdot 0$, sedimented at $100000 \mathrm{~g}$ for $1 \mathrm{~h}$ at $4^{\circ} \mathrm{C}$ in a Hitachi RP50 rotor, washed once and suspended in the same buffer. The density of each gradient fraction was determined with an Atago Abbe refractometer.

Assay of penicillin-binding proteins. $\left[{ }^{14} \mathrm{C}\right]$ Penicillin G binding, SDS-PAGE and subsequent fluorography were carried out as described previously (Bonner \& Laskey, 1974; Laskey \& Mills, 1975; Koyasu et al., 1980, 1981, 1982; 
Fukuda et al., 1981). The reference proteins used for apparent molecular weight determination were $C$. crescentus CB13 RNA polymerase subunits $\beta^{\prime}(165000)$ and $\beta$ (155000), bovine serum albumin (67000), ovalbumin (46000), chymotrypsinogen A (25000), whale myoglobin (17800) and horse cytochrome $c$ (12400).

Miscellaneous. Proteins were assayed by the Lowry method using bovine serum albumin as the standard. Succinate dehydrogenase activity was assayed as described (Koyasu et al., 1980). The reaction mixture (0.9 $\mathrm{ml})$

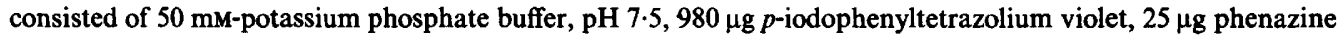
methosulphate, $770 \mu \mathrm{g}$ gelatin and 10 to $80 \mu \mathrm{g}$ sample. After incubation at $30^{\circ} \mathrm{C}$ for $10 \mathrm{~min}, 0.1 \mathrm{ml} 0.2 \mathrm{M}$-sodium succinate was added and the mixture was incubated again at $30^{\circ} \mathrm{C}$ for $10 \mathrm{~min}$. The mixture was rapidly cooled on

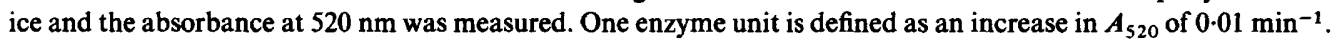

Minimum inhibitory concentrations $\left(\mathrm{MIC}_{50}\right)$ and effects on cell morphology of $\beta$-lactam antibiotics were observed as described previously (Koyasu et al., 1981).

Electron microscopy was carried out as follows. Samples were applied to a carbon film on a copper grid (400

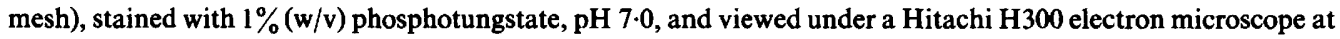
$75 \mathrm{kV}$.

Chemicals. $\left[{ }^{14} \mathrm{C}\right]$ Penicillin $\mathrm{G}\left(50\right.$ to $60 \mathrm{Ci} \mathrm{mol}^{-1}, 1 \cdot 85$ to $\left.2 \cdot 22 \mathrm{TBq} \mathrm{mol}^{-1}\right)$ and penicillin $\mathrm{V}$ were purchased from Amersham and Sigma, respectively. Other $\beta$-lactam antibiotics were generous gifts from many sources: apalcillin, Sumitomo Chemical Co., Osaka, Japan; cefazolin, Fujisawa Pharmaceutical Industries Co., Osaka; cephaloglycin, Shionogi Pharmaceutical Co., Osaka; penicillin G and cloxacillin, Meiji Seika Co., Tokyo; mecillinam, Leo Pharmaceutical Products, Denmark; 6-aminopenicillanic acid, piperacillin, methicillin, hetacillin, carbenicillin, sulbenicillin, oxacillin, dicloxacillin, cephalothin, cefsulodin, cefoxitin and cefmetazole, Sankyo Pharmaceutical Co., Tokyo.

\section{RESULTS}

\section{Properties of isolated stalks}

Shed stalks of an abscission mutant, CB15 NY106, and sheared stalks of CB15 wild-type were prepared by repeated differential centrifugation and observed under an electron microscope (Fig. 1). The shed stalks of CB15 NY106 possessed a swelling at one pole, which had been proximal to the cell (Poindexter \& Hagenzieker, 1982).

To examine the density of the stalk, intact or sonicated stalk preparation was centrifuged in an isopycnic sucrose density gradient. Shed stalks were sedimented through the gradient to a position between outer $\left(1.24 \mathrm{~g} \mathrm{~cm}^{-3}\right)$ and inner $\left(1.19 \mathrm{~g} \mathrm{~cm}^{-3}\right)$ membranes (Koyasu et al., 1980). The density was $1.225 \mathrm{~g} \mathrm{~cm}^{-3}$, closer to that of the outer membrane fractions. Both intact and sonicated stalk showed the same density. In addition, both sonicated and intact stalks sheared from CB15 wild-type also sedimented in an isopycnic sucrose density gradient to the same density level (data not shown).

Pure and intact stalks from the sucrose gradient were sonicated and assayed for the activity of succinate dehydrogenase, a typical marker enzyme of the cytoplasmic membrane (Osborn et al., 1972). The specific activity in the sonicated stalk preparation was very low $[2.9$ units (mg protein $)^{-1}$ ], while 148 and 17 units (mg protein) $)^{-1}$ were observed in cellular inner and outer membrane preparations, respectively (Koyasu et al., 1980).

Stalk proteins were analysed by SDS-PAGE. The protein pattern of the stalk was quite similar to that of the outer membrane (data not shown). All of these results consistently imply that the stalk membrane of $C$. crescentus CB15 comprises mainly outer membranes.

\section{Penicillin-binding proteins of stalks}

Peptidoglycan is the skeletal structure of the stalk, as of the cell wall (Poindexter \& CohenBazire, 1964; Schmidt \& Stanier, 1966; Poindexter \& Hagenzieker, 1982). To investigate whether new and/or specific PBPs are present in the stalk, PBPs in the isolated stalks of CB15 wild-type and CB15 NY106 were assayed. The patterns of PBPs in the stalks were quite different from those in cell envelopes (Fig. 2). PBP 1A and PBP 3 which are present mostly in the inner membrane (Koyasu et al., 1980) were not detectable in the stalks. This result is further evidence that the stalk contains mainly outer membranes. Two minor PBPs found in the total cell envelope (containing both cell envelopes and stalks) which migrate between PBP 1 Bs and PBP 2, were enriched greatly in the isolated stalk fraction. These PBPs were designated PBP X (mol. wt 93000) and PBP Y (mol. wt 85000). Some of the other minor bands were also seen in the 

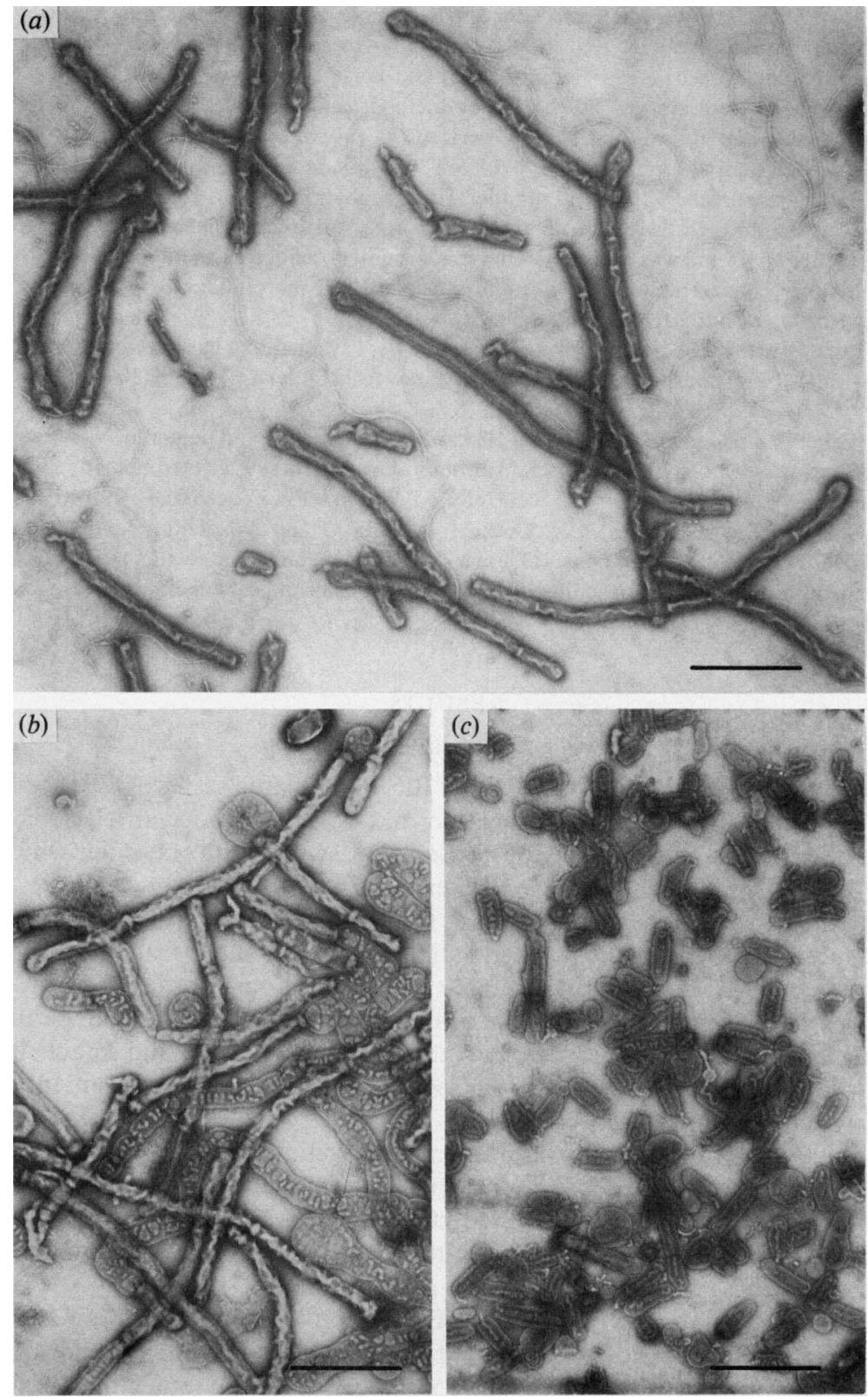

Fig. 1. Isolated stalks of $C$. crescentus. Shed stalks of $(a) C$. crescentus CB15 NY106, and (b) sheared stalks of CB15 wild-type were prepared by repeated differential centrifugation as described in Methods. Purified stalks of CB15 NY106 were sonicated (c). Samples were stained with $1 \%$ phosphotungstate and observed under a Hitachi $\mathrm{H} 300$ electron microscope. The bar markers represent $1 \mu \mathrm{m}$.

stalk. One of them was a band of molecular weight 55000 which might correspond to PBP S1 (Koyasu et al., 1982) in the soluble fraction. Similar results were obtained in an abscission mutant, C. crescentus CB2 NY66 (Poindexter, 1978) (data not shown).

Binding kinetics of $\left[{ }^{14} \mathrm{C}\right]$ penicillin $G$ to PBP X and PBP Y were measured. The concentrations of $\left[{ }^{14} \mathrm{C}\right]$ penicillin $\mathrm{G}$ in the reaction mixture were varied, and the amounts of the bound ${ }^{14} \mathrm{C}$ radioactivity were measured by densitometry of exposed films. [ $\left.{ }^{14} \mathrm{C}\right] P$ Penicillin $\mathrm{G}$ did not show high affinity for either PBP X or PBP Y, and the binding was not saturated even at 


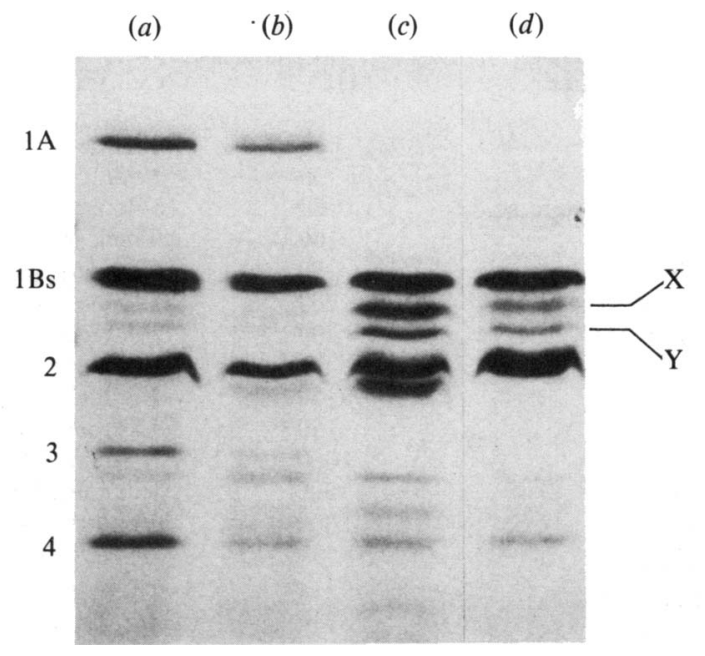

Fig. 2. PBPs of isolated stalks. Cell envelopes of CB15 wild-type from (a) PYE culture, or (b) $\mathrm{HiGg}$ culture, and stalks of $(c)$ CB15 wild-type or $(d)$ CB15 NY106 from HiGg cultures were prepared as described in the text. Samples were treated with $\left[{ }^{14} \mathrm{C}\right]$ penicillin $\mathrm{G}$, and subjected to SDS-PAGE $(7 \cdot 5 \%$ acrylamide) and subsequent fluorography. The numbers on the left-hand side are the designations of major PBPs in the cell envelope; those on the right-hand side are the designations of the new PBPs detected in the isolated stalks. [The band below PBP 2 in $(c)$ was not consistently seen and is tentatively regarded as an artefact of unknown origin.]

$100 \mu \mathrm{g}\left[{ }^{14} \mathrm{C}\right]$ penicillin $\mathrm{G} \mathrm{ml} \mathrm{m}^{-1}$; the amounts of bound $\left[{ }^{14} \mathrm{C}\right]$ penicillin $\mathrm{G}$ to PBP X and PBP Y were $30 \%$ and $20 \%$, respectively, of the amounts at $300 \mu \mathrm{g}\left[{ }^{14} \mathrm{C}\right]$ penicillin $\mathrm{G} \mathrm{ml}^{-1}$. These PBPs seemed to bind more $\left[{ }^{14} \mathrm{C}\right]$ penicillin $\mathrm{G}$ when the concentration of the antibiotic was increased above $300 \mu \mathrm{g} \mathrm{ml}^{-1}$.

\section{Effect of $\beta$-lactam antibiotics on stalk development}

It is important, for the elucidation of the functions of PBPs, to investigate any correlation between the affinities for PBPs and the effects on cell morphology of $\beta$-lactam antibiotics. As shown above, $\left[{ }^{14} \mathrm{C}\right]$ penicillin $G$ had low affinity for PBP X and PBP Y and did not saturate the PBPs even at $100 \mu \mathrm{g} \mathrm{ml}^{-1}$. The use of the pre-addition method (Spratt, 1975; Koyasu et al., 1981) may not be suitable for the examination of the affinity of $\beta$-lactam antibiotics. Instead, the simultaneous addition (competitive inhibition) method is suitable for determination of the relative affinities of $\beta$-lactam antibiotics such as apalcillin, cloxacillin, mecillinam, cephaloridine, cephalexin, cephaloglycin and cefazolin. By this method, relative affinities of $\beta$-lactam antibiotics can be compared with that of $\left[{ }^{14} \mathrm{C}\right]$ penicillin $\mathrm{G}$. Most of the above antibiotics did not show higher affinity for PBP X or PBP Y than did pencillin G; they did not bind to PBP X nor PBP Y, even at $5 \mathrm{mg} \mathrm{ml}^{-1}$, when, mixed together with $100 \mu \mathrm{g}\left[{ }^{14} \mathrm{C}\right]$ penicillin $\mathrm{G} \mathrm{ml}^{-1}$. Only apalcillin showed similar affinity to that of penicillin G; concentrations needed for the $50 \%$ inhibition of $\left[{ }^{14} \mathrm{C}\right]$ penicillin $\mathrm{G}$ binding to PBP X and PBP Y were 140 and $700 \mu \mathrm{g} \mathrm{ml}^{-1}$, respectively.

The effect of $\beta$-lactam antibiotics on stalk development was examined and the $\mathrm{MIC}_{50}$ values and effects on cell morphology of these antibiotics are summarized in Table 1. None of them caused inhibition of stalk development without also causing inhibition of cell division and subsequent filament formation. This result is consistent with the notion that stalk development is a cell division-dependent step (Terrana \& Newton, 1976; Osley \& Newton, 1977), or that it is dependent on the same processes on which cell division depends. At low concentrations of $\beta$ lactam antibiotics that did not induce filament formation, none of the antibiotics inhibited stalk development as might be expected from the fact that affinities of the above $\beta$-lactam antibiotics for PBP X and PBP Y were much weaker than for PBP 3 which had been suggested to be 
Table 1. MIC 50 and effect of $\beta$-lactam antibiotics on cell morphology of C. crescentus CB15

\begin{tabular}{l}
\multicolumn{1}{c}{ Antibiotics } \\
Penicillins \\
Penicillin G \\
Penicillin V \\
6-Aminopenicillanic acid \\
Mecillinam \\
Apalcillin \\
Piperacillin \\
Methicillin \\
Hetacillin \\
Carbenicillin \\
Sulbenicillin \\
Oxacillin \\
Cloxacillin \\
Dicloxacillin \\
Cephalosporins \\
Cephaloridine \\
Cephalexin \\
Cephalothin \\
Cephaloglycin \\
Cefazolin \\
Cefsulodin \\
Cephamycins \\
Cefoxitin \\
Cefmetazole
\end{tabular}

$\begin{aligned} \text { MIC }_{50}{ }^{*} & \text { Cell morphologyt } \\ 20 & \text { Filament (5) } \\ 30 & \text { Filament (10) } \\ 50 & \text { Filament (10) } \\ 100 & \text { Thick (80) } \\ 50 & \text { Filament (10) } \\ 200 & \text { Filament (10) } \\ 200 & \text { Filament (50) } \\ 80 & \text { Filament (10) } \\ 150 & \text { Filament (20) } \\ 150 & \text { Filament (30) } \\ 1000 & \text { Filament (300) } \\ 500 & \text { Filament (100) } \\ 300 & \text { Filament (100) } \\ & \\ 5 & \text { Lysis } \\ 5 & \text { Filament (1) } \\ 8 & \text { Lysis } \\ 15 & \text { Lysis } \\ 30 & \text { Lysis } \\ 80 & \text { Lysis } \\ 30 & \\ 80 & \text { Filament (10) } \\ & \text { Filament (40) }\end{aligned}$

* See Koyasu et al. (1981).

+ Numbers in parentheses represent the lowest concentrations $\left(\mu \mathrm{g} \mathrm{ml}^{-1}\right)$ at which the morphological effect was observed.

involved in cell division (Koyasu et al., 1981). The stalk contains crossbands that are sensitive to lysozyme (Schmidt, 1973). The formation of these crossbands was not inhibited by $\beta$-lactam antibiotics used here at a similar low concentration. In the presence of cephaloridine, which did not induce filament formation (Table 1), synchronous swarmer cells prepared as described previously (Degnen \& Newton, 1972; Iba et al., 1977) developed stalks after incubation at $30^{\circ} \mathrm{C}$ for $60 \mathrm{~min}$ in PYE broth. Mecillinam, which induces spherical cells in Escherichia coli, caused an increase in cell diameter in $C$. crescentus, a delay in separation of constricted cells, and a marked reduction in stalk outgrowth (Fig. 3). However, at lower concentrations where thickening of the cell and suspension of constriction were not observed, stalk outgrowth was also unaffected. Accordingly, none of the $\beta$-lactam antibiotics tested were found to be specific inhibitors of stalk development in C. crescentus.

\section{PBPs of a stalk-defective mutant}

PBP X and PBP Y are enriched in the stalk. A priori it is possible that they are involved in the stalk development. It was, therefore, of interest to determine whether stalk-defective mutants would be deficient in PBP X and/or PBP Y.

Caulobacter crescentus CB15 str-802 was mutagenized with $N$-methyl- $N^{\prime}$-nitro- $N$-nitrosoguanidine according to the procedure described previously (Fukuda et al., 1974, 1981). Survivors were plated on $1 \%$ agar-PYE medium containing $300 \mu \mathrm{g}$ mecillinam $\mathrm{ml}^{-1}$. Mecillinam-resistant colonies appeared at a frequency of $10^{-4}$. Most of about 200 mutants examined appeared to be permeability mutants whose morphology was indistinguishable from that of the parent strain. However, one of the mutants, designated CB15 mcr-816, lacked elongated stalks (Fig. 4). Cell envelopes of this mutant were prepared from PYE culture and PBPs were assayed. While the cell envelopes of CB15 mcr-816 contained major PBPs (PBP 1A, PBP 1Bs, PBP 2, PBP 3 and PBP 4), only very small amounts of PBP X and PBP Y were observed (Fig. 5). The amount of PBP $X$, in particular, was negligible in the cell envelopes. This result is consistent with the identification of PBP X and PBP Y as proteins localized in normal stalks. 

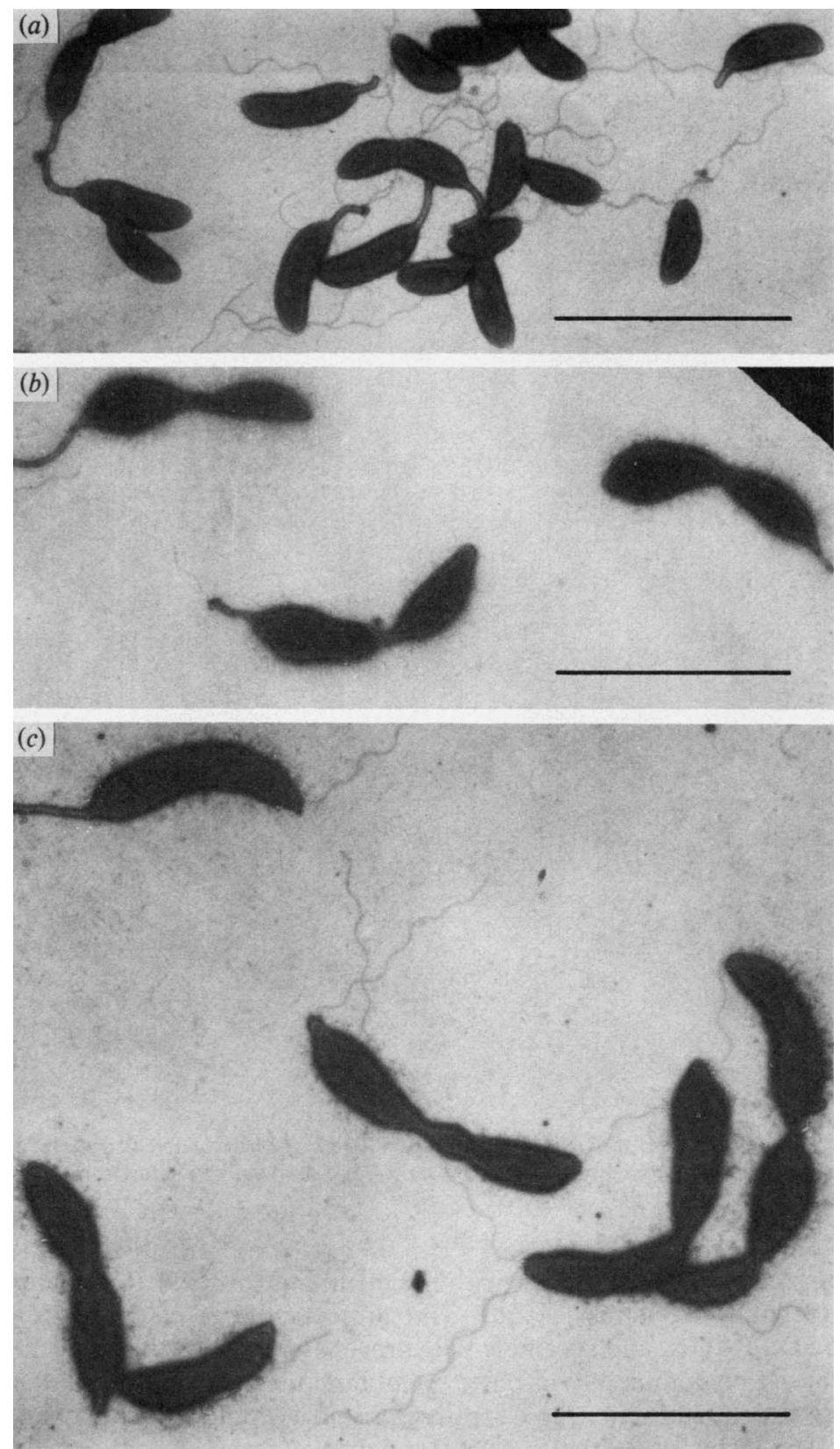

Fig. 3. Mecillinam effect on Caulobacter cell morphology. CB15 wild-type was grown in (a) PYE broth, or PYE broth containing (b) $100 \mu \mathrm{g}$ mecillinam ml-1, or (c) $150 \mu \mathrm{g}$ mecillinam $\mathrm{ml}^{-1}$. After $12 \mathrm{~h}$, cells were observed under an electron microscope. The bar markers represent $5 \mu \mathrm{m}$.

\section{DISCUSSION}

In this paper, we have described several properties of the isolated stalks of C. crescentus CB15, as well as the newly recognized PBPs that are enriched in the stalk. It was previously reported (Poindexter \& Cohen-Bazire, 1964; Schmidt \& Stanier, 1966) that the stalk consists of outer membrane, peptidoglycan and cytoplasmic membrane. Cytoplasmic membranes were observed 

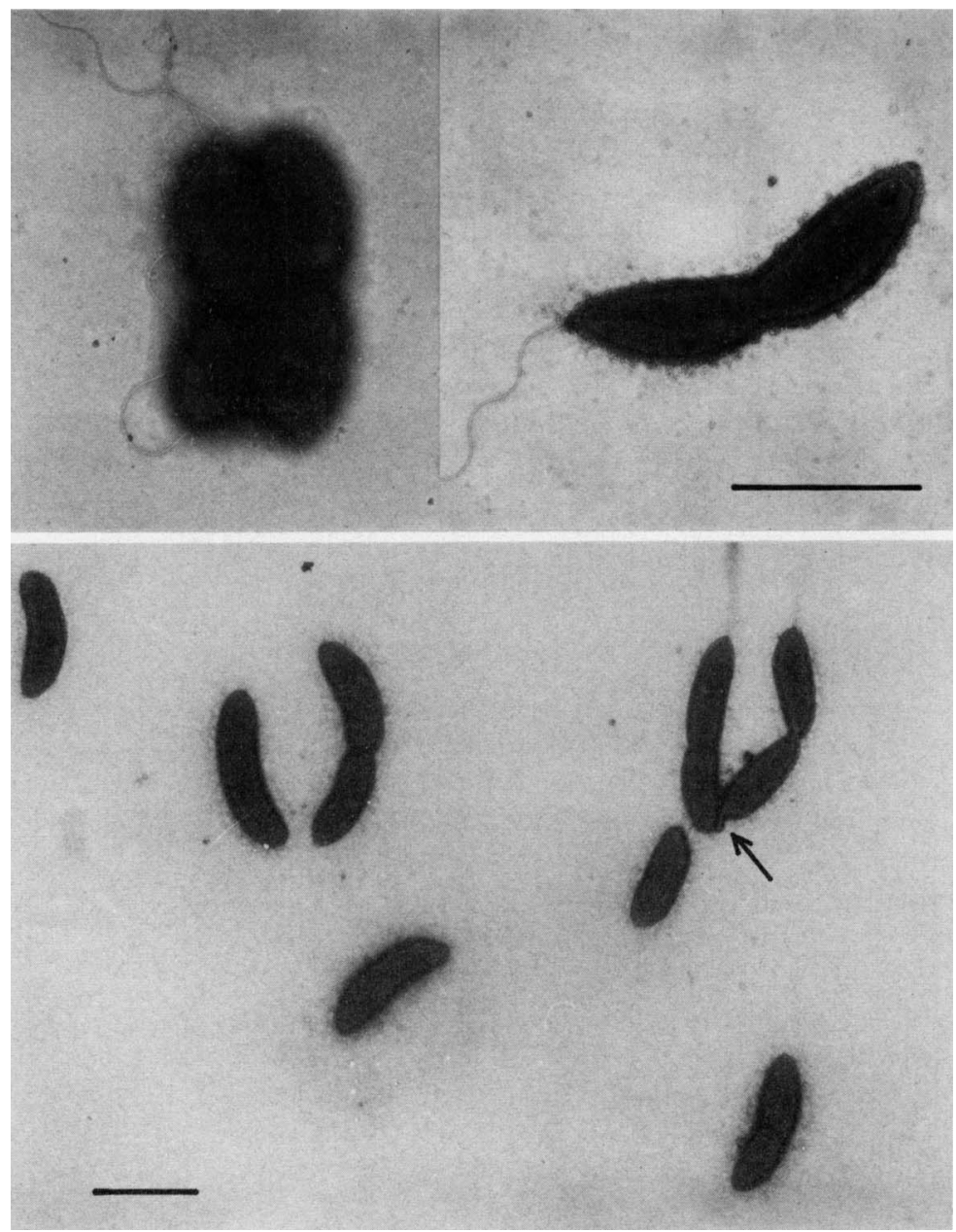

Fig. 4. A mecillinam-resistant stalk-defective mutant, CB15 mcr- 816 , isolated as described in the text. Cells were harvested from PYE culture. The arrow indicates a short stalk structure sometimes observed. The bar markers represent $2 \mu \mathrm{m}$.

by electron microscopy to be continuous with the membrane of the cell (Poindexter \& CohenBazire, 1964; Schmidt \& Stanier, 1966). The present studies show by density gradient centrifugation, SDS-PAGE, and succinate dehydrogenase content, that the stalk membranes are found to consist predominantly of outer membrane material. Prosthecae of Asticcacaulis biprosthecum are structurally similar to C. crescentus stalks (Poindexter \& Cohen-Bazire, 1964; Pate \& Ordal, 1965; Schmidt \& Stanier, 1966), and display fewer proteins in SDS-PAGE than whole-cell envelopes (Jordan et al., 1974). Thus, differences between the organelles appear to be minor as characterized so far.

Extensive studies on the PBPs of $E$. coli have revealed that PBPs of this bacterium play specific roles, e.g., PBP 1A and PBP 1Bs in cell elongation, PBP 3 in cell division, and PBP 2 in maintenance of cell shape. It has not been possible to show, however, whether specific PBPs are localized in the cell at the sites where they exert their respective functions. In order to approach this problem, Buchanan studied the PBPs of E. coli minicells, whose walls are considered to be derived from septum materials due to the minA mutation (Buchanan, 1981). Some differences were observed between the patterns of PBPs of whole cells and of minicells. For example, in minicells there were reduced amounts of PBP 2; there were also two bands of PBP 1Bs, rather 
(a)

(b)

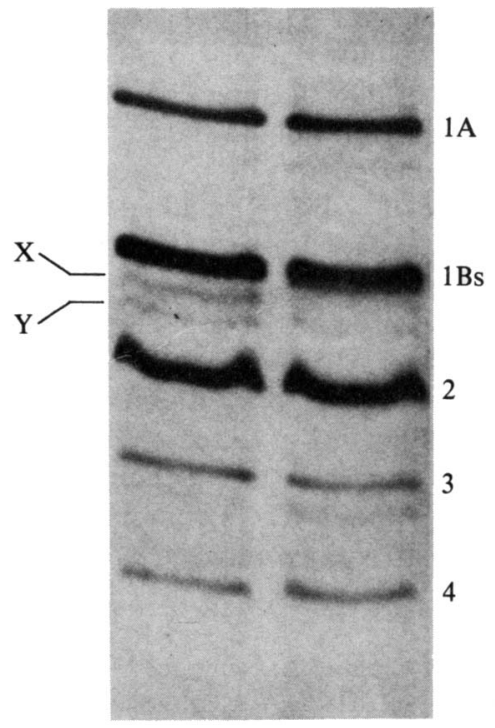

Fig. 5. PBPs of CB15 mcr-816. Cell envelopes of (a) CB15 wild-type or (b) CB15 mcr-816 were treated with $\left[{ }^{14} \mathrm{C}\right]$ penicillin $\mathrm{G}$ and then PBPs were analysed as described in Methods. The lettering is as in Fig. 2.

than the usual three. However, seven major PBPs were observed in both whole cells and minicells, and large differences were not observed.

To investigate such a problem of functional localization, $C$. crescentus offers a unique opportunity. As shown in the present study, PBPs of the stalk are different from those of the total cell envelope. The apparent absence of PBP 1A and PBP 3 from stalks may reflect the low proportion of inner membrane in stalks, since these PBPs can be demonstrated only in inner membrane fractions (Koyasu et al., 1980). These two proteins are greatly reduced in stationaryphase cells, especially in HiGg-grown populations (see Fig. 2). Since stalks were prepared from late exponential (sheared) and stationary phase (shed) populations grown in $\mathrm{HiGg}$, the apparent absence of PBP 1A and PBP 3 from the stalk may be due to the medium or growth phase, rather than the fact that these PBPs are not among stalk components. PBP 1 Bs and PBP 2 are found in both membrane fractions, while PBP 4 appears to be localized in outer membrane (Koyasu et al., 1980); all three of these proteins were detectable in stalks.

On the other hand, two PBPs present in minor amounts in cell envelopes grown in either PYE or HiGg medium were markedly enriched in stalk preparations. These two proteins, PBP X and PBP Y, appear to be localized in the stalk. The stalk-defective mutant CB15 mcr-816 possesses only very low levels of PBP X and PBP Y. These small amounts could be accounted for by the presence of short stalks on about 5 to $10 \%$ of the mutant cells in PYE broth (Fig. 4, arrowed). In contrast, $80 \%$ of CB15 wild-type cells possess long stalks. Since stalks elongate at the juncture between stalk and cell body (Schmidt \& Stanier, 1966), enzymes involved in stalk development might be present within the juncture. The mutant CB15 NY106 sheds its stalks with a swelling that appears to arise from the juncture (Poindexter, 1978; Poindexter \& Hagenzieker, 1982; Fig. 1), and stalks sheared from CB15 wild-type seem not to contain the juncture. Comparison of the stalks from these two different sources did not reveal any fundamental differences in the patterns of PBPs, implying that PBP X and PBP Y are probably distributed along the length of the stalk, and are not localized within the cell-stalk juncture.

To attempt to determine whether PBP X and/or PBP Y could be involved in stalk development and/or crossband formation, the correlation between affinity for PBPs and effect on the cell morphology of specific $\beta$-lactam antibiotics was investigated. A total of $21 \beta$-lacatam 
antibiotics were examined (Table 1), but none of them showed either a high affinity for PBP X and PBP Y, or a specific morphological effect involving stalk development alone.

Stalk peptidoglycan has been found to differ from cellular peptidoglycan by containing a significantly higher proportion of glucosamine (Poindexter \& Hagenzieker, 1982). The localization of PBP X and PBP Y specifically in the stalk implies that these proteins might be involved in determining the peculiar composition of stalk peptidoglycan. In E. coli, PBP 1A, PBP 1Bs and PBP 3 have been shown to be bifunctional peptidoglycan synthetic enzymes, with both transglycosylase and transpeptidase activities (Nakagawa et al., 1979; Ishino et al., 1980; Suzuki et al., 1980; Tamura et al., 1980; Ishino \& Matsuhashi, 1981 ; Nakagawa \& Matsuhashi, 1982). PBPs in general may prove to be bifunctional enzymes. If the PBPs localized in the $C$. crescentus stalk are enzymically active, they may be directly involved in stalk development either by (1) synthesis of a glycan chain different from that found in cellular peptidoglycan, or, equally possible, by (2) post-synthetic modification of the peptidoglycan at the stalked pole. Purification of the $C$. crescentus PBPs and characterization of their respective enzymic activities will be necessary to resolve their roles in peptidoglycan synthesis and/or modification, and to clarify the significance of their differential distributions between outer and inner membranes, and between cell body and stalk.

This work was supported in part by a Grant-in-Aid from the Ministry of Education, Sciences and Culture of Japan, and by Public Health Service grant AI-15467 from the National Institutes of Health, U.S.A.

\section{REFERENCES}

Bonner, W. M. \& LASKey, R. A. (1974). A film detection method for tritium-labelled proteins and nucleic acids in polyacrylamide gels. European Journal of Biochemistry 46, 83-88.

BuChaNAN, C. E. (1981). Topographical distribution of penicillin-binding proteins in the Escherichia coli membrane. Journal of Bacteriology 145, 1293-1298.

Degnen, S. T. \& Newton, A. (1972). Chromosome replication during development in Caulobacter crescentus. Journal of Molecular Biology 64, 671-680.

Fukuda, A., Miyakawa, K. \& Okada, Y. (1974). A pleiotropic mutation in Caulobacter crescentus that affects the flagellar formation and susceptibility to phage infection. Proceedings of the Japan Academy 50, 839-842.

Fukuda. A., Asada, M., Koyasu, S., Yoshida, H., YAGINUMA, K. \& OKaDA, Y. (1981). Regulation of polar morphogenesis in Caulobacter crescentus. Journal of Bacteriology 145, 559-572.

IBA, H., Fukuda, A. \& OKadA, Y. (1977). Chromosome replication in Caulobacter crescentus growing in a nutrient broth. Journal of Bacteriology 129, 11921197.

Ishino, F. \& Matsuhashi, M. (1981). Peptidoglycan synthetic enzyme activities of highly purified penicillin-binding protein 3 in Escherichia coli: a septumforming reaction sequence. Biochemical and Biophysical Research Communications 101, 905-911.

Ishino, F., Mitsui, K., Tamaki, S. \& Matsuhashi, M. (1980). Dual enzyme activities of cell wall peptidoglycan synthesis, peptidoglycan transglycosylase and penicillin-sensitive transpeptidase, in purified preparations of Escherichia coli penicillin-binding protein 1A. Biochemical and Biophysical Research Communications 97, 287-293.

JONES, H. C. \& ScHMIDT, J. M. (1973). Ultrastructural study of crossbands occurring in the stalks of Caulobacter crescentus. Journal of Bacteriology 116, 466- 470 .
Jordan, T. L., Porter, J. S. \& Pate, J. L. (1974). Isolation and characterization of prosthecae of Asticcacaulis biprosthecum. Archives of Microbiology 96, 1-16.

Koyasu, S., Fukuda, A. \& OKada, Y. (1980). The penicillin-binding proteins of Caulobacter crescentus. Journal of Biochemistry 87, 363-366.

Koyasu, S., Fukuda, A. \& OKadA, Y. (1981). Properties of the penicillin-binding proteins of Caulobacter. Journal of General Microbiology 126, 111-121.

Koyasu, S., Fukuda, A. \& OKada, Y. (1982). Penicillin-binding proteins in the soluble fraction of Caulobacter crescentus. Journal of General Microbiology 128, 1117-1124.

LASKey, R. A. \& Mills, A. D. (1975). Quantitative film detection of ${ }^{3} \mathrm{H}$ and ${ }^{14} \mathrm{C}$ in polyacrylamide gels by fluorography. European Journal of Biochemistry 56, 335-341.

Nakagawa, J. \& MatsuHashi, M. (1982). Molecular divergence of a major peptidoglycan synthetase with transglycosylase-transpeptidase activities in Escherichia coli-penicillin-binding protein 1Bs. Biochemical and Biophysical Research Communications 105, 1546-1553.

Nakagawa, J., Tamaki, S. \& Matsuhashi, M. (1979). Purified penicillin binding proteins $1 \mathrm{Bs}$ from Escherichia coli membrane showing activities of both peptidoglycan polymerase and peptidoglycan crosslinking enzymes. Agricultural and Biological Chemistry 43, $1379-1380$.

Osborn, M. J., Gander, J. E., Parisi, E. \& Carson, J. (1972). Mechanism of assembly of the outer membrane of Salmonella typhimurium. Isolation and characterization of cytoplasmic and outer membrane. Journal of Biological Chemistry 247, 39623972.

Osley, M. A. \& Newton, A. (1977). Mutational analysis of developmental control in Caulobacter 
crescentus. Proceedings of the National Academy of Sciences of the United States of America 74, 124-128.

Pate, J. L. \& ORdal, E. J. (1965). The fine structure of two unusual stalked bacteria. Journal of Cell Biology 27, 133-150.

PoINDEXTER, J. S. (1964). Biological properties and classification of the Caulobacter group. Bacteriological Reviews 28, 231-295.

PoINDEXTER, J. S. (1978). Selection for nonbuoyant morphological mutants of Caulobacter crescentus. Journal of Bacteriology 135, 1141-1145.

PoINDEXTER, J. S. (1981). The caulobacters: ubiquitous unusual bacteria. Microbiological Reviews 45, 123 179.

Poindexter, J. S. \& Cohen-Bazire, G. (1964). The fine structure of stalked bacteria belonging to the family caulobacteraceae. Journal of Cell Biology 23, $587-607$

Poindexter, J. S. \& Hagenzieker, J. G. (1982). Novel peptidoglycans in Caulobacter and Asticcacaulis spp. Journal of Bacteriology 150, 332-347.

Schimi, J. M. (1973). Effect of lysozyme on crossbands in stalks of Caulobacter crescentus. Archives of Microbiology 89, 33-40.

SchmidT, J. M. \& Stanier, R. Y. (1966). The development of cellular stalks in bacteria. Journal of Cell Biology 28, 423-436.

ShapIRo, L. (1976). Differentiation in the Caulobacter cell cycle. Annual Review of Microbiology 30, 377407.

SPRATT, B. G. (1975). Distinct penicillin binding proteins involved in the division, elongation and shape of Escherichia coli K12. Proceedings of the National Academy of Sciences of the United States of America 72, 2999-3003.

SPRATT, B. G. (1977a). Properties of the penicillin- binding proteins of Escherichia coli K12. European Journal of Biochemistry 72, 341-352.

SpraTT, B. G. (1977b). Temperature-sensitive cell division mutants of Escherichia coli with thermolabile penicillin-binding proteins. Journal of Bacteriology 131, 293-305.

Spratt, B. G. \& Pardee, A. B. (1975). Penicillinbinding proteins and cell shape in E. coli. Nature, London 254, 516-517.

Suzuki, H., Nishimura, Y. \& Hirota, Y. (1978). On the process of cellular division in Escherichia coli: a series of mutants of $E$. coli altered in the penicillinbinding proteins. Proceedings of the National Academy of Sciences of the United States of America 75, 664-668.

Suzuki, H., van Heinenoort, Y., Tamura, T., Mizoguchi, J., Hirota, Y. \& van HeiJenoort, J. (1980). In vitro peptidoglycan polymerization catalyzed by penicillin-binding protein $1 \mathrm{~b}$ of Escherichia coli $\mathrm{K}-12$. FEBS Letters 110, 245-249.

Tamaki, S., NaKaima, S. \& MatsuHashi, M. (1977). Thermosensitive mutation in Escherichia coli simultaneously causing defects in penicillin-binding protein-1Bs and in enzyme activity for peptidoglycan synthesis in vitro. Proceedings of the National Academy of Sciences of the United States of America 74, 5472-5476.

Tamura, T., Suzuki, H., Nishimura, Y., Mizoguchi, J. \& Hirota, Y. (1980). On the process of cellular division in Escheriuhia coli: isolation and characterization of penicillin-binding proteins $1 \mathrm{a}, \mathrm{lb}$, and 3 . Proceedings of the National Academy of Sciences of the United States of America 77, 4499-4503.

Terrana, B. \& Newton, A. (1976). Requirement of a cell division step for stalk formation in Caulobacter crescentus. Journal of Bacteriology 128, 456-462. 